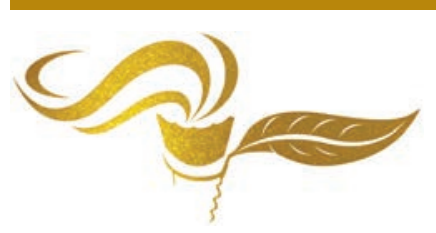

\title{
Conceptualizing Trans Well-being within Transdisciplinarity
}

\section{Sue L. T. McGregor}

ATLAS Fellow, Professor Emerita (MSVU), McGregor Consulting Group (Principal Consultant), 11565 Peggy's Cove Road, Seabright Nova Scotia Canada B3Z 2Y1, Email:sue.mcgregor@msvu.ca or www.consultmcgregor.com

Received 5 November, 2019; Revised 21 December, 2019; Accepted January 15, 2020

Available online 20 January, 2020 at www.atlas-journal.org, doi: 10.22545/2020/00130

\begin{abstract}
A fter describing conventional approaches to well-being (hedonic and eudaimonic, subjective and objective) and explaining the four philosophical axioms of Nicolescuian transdisciplinarity (TD), this conceptual research paper identified and juxtaposed four alternative approaches to well-being against Nicolescuian TD: social conception, self-transcendent, intra-active, and relational well-being. The notion of prototypical (lay) well-being was also introduced. What might well-being look like within transdisciplinarity? The paper concluded that trans well-being (a new term) would be a process that is situated, contextual and emergent. It would always be unfolding and becoming, arising with and through others. Trans well-being would be a state of being with others (and the environment) and might even be a form of epistemic self-discovery (insights into psyche and self). Upon embracing Nicolescuian TD, perceptions of well-being may have to shift from a state of being to a process of being with others in perpetual evolution.
\end{abstract}

Keywords: Well-being, Nicolescuian transdisciplinarity, conceptual research, trans well-being, prototypical well-being, alternative conceptualizations of well-being.

\section{Introduction}

Given the current state of the postnormal world, characterized by chaotic change and crises along with opportunities to mitigate the complex, uncertain situation (McGregor, 2016) [1], humanity's well-being is front and center (Apgar, Argumendo,\& Allen, 2009) [2]. Well-being is already a "complex philosophical and political concept" (Smith \& Reid, 2017, p. 7 [3]). Enter transdisciplinarity (TD) wherein Efthimiou (2017) [4] referred to "the development of transdisciplinary wellbeing frameworks" (p. 34). McIntyre-Mills (2014) [5] spoke of "transdisciplinarity and a reframed approach to wellbeing" (p. 75). This nascent line of thinking stimulated this paper about what might constitute the conceptualization of well-being within transdisciplinarity.

In particular, this paper reports on conceptual research, which serves to relate specific concepts to particular issues (in this case, well-being to transdisciplinarity) with the intent to both map the research terrain evolving around the concept and better define it (Rocco \& Plakhotnik, 2009) [6]. Conceptual 
scholarship contributes significantly to any discipline's intellectual renewal and evolution (Smithey Fulmer, 2012) [7]. After describing longstanding conventional approaches to well-being and profiling the Nicolescuian TD approach, four alternative conceptualizations of well-being are explained and juxtaposed against transdisciplinarity. The idea of well-being as prototypical is also introduced as one that pushes back against both generic and alternative approaches.

Transdisciplinary and other scholars are encouraged to critically reflect on and engage with the ideas shared in this paper. Mitstifer (1996) [8]appreciated the intellectual angst that can arise during this sort of philosophical exercise, cautioning that reframing "well-being . . . will take time, suspended assumptions, and collegial regard for the development of a free flow of meaning and of windows to new understandings" (p. v). As caveat, the word can be hyphenated (well-being) or not (wellbeing) depending on usage in different parts of the world (Grammarist, 2013) [9]. The author used the hyphenated version while respecting the version used in sources cited.

\section{Conventional Approaches to Well-Being}

There is no firm agreement on what constitutes well-being (Gasper, 2004 [10]; Hone, Schofield, \& Jarden, 2015 [11]; McGregor, 2010b [12]). But generally speaking, compared to wellness, which is a dynamic process, well-being is a state of being, a condition of being happy, healthy and prosperous at a particular time (King, 2007) [13]. To illustrate, well-being is "a state of being where [people] have economic security; are respected, valued and have personal worth; feel connected to those around them; are able to access necessary resources; and are able to participate in the decision-making process affecting them" (Marshall, McMullin, Ballantyne, Daciuk, \& Wigdor, 1995, p.1 [14]).

Two overarching approaches to well-being have emerged in the literature and practice: (a) hedonic, also called subjective well-being (SWB) and (b) eudaimonic or objective well-being (OWB) (Belzak, Thrash, Sim, \& Wadsworth, 2017 [15]; McMahan \& Estes, 2011 [16]). These conceptualizations need to be understood before considering alternative approaches that can be aligned with transdisciplinary tenets.

\subsection{Subjective and Objective Well-being}

Subjective well-being concerns people's assessment of their own state of being at a particular point in time. They evaluate and then judge both their life satisfaction (cognitive state) and happiness or unhappiness (emotional state). The different circumstances and conditions of a person's life determine their resultant self-assessment. Objective well-being focuses on third-party assessment of other people's quality of life and the good life including the latter's access to both (a) material resources (e.g., income, food, housing) and (b) social attributes (e.g., education and health) and connections (i.e., social networks, political voice and inclusion) (Smith \& Reid, 2017 [3]; Western \& Tomaszewski, 2016 [17]).

In more detail, the objective approach assumes that people have basic needs and rights that can be objectively (third person) observed so as to discern the extent to which they are being satisfied. Measurable indicators include income, employment, health, housing and education. Lists of objective well-being measures are well established in the literature. Things appear or not on the list because researchers have assumed that they are good and bad for well-being causing this approach to be characterized as paternalistic. The subjective approach tries to eschew paternalism by directly asking people what they think and feel about their own state of well-being; this involves self-reporting how satisfied people are with their lives (Qizilbash, 2009 [18]; Smith \& Reid, 2017 [3]; see also Sianf's (2011) [19] blog posting at the United Kingdom's Office of National Statistics' wellbeing consultation site).

\subsection{Hedonic Well-being}

Hedonic is Greek hedone, "pleasure" (Harper, 2019) [20]. The hedonic approach (SWB) equates well-being with pleasure, happiness, satisfaction and utility (Gasper, 2004 [10]; McMahan \& Estes, 2011 [16]; Smith \& Reid, 2017 [3]). It is referred to as "a life of gratification" (Smith \& Reid, 2017, p. 4 [3]). "In short, the 
hedonia tradition frames being well in terms of feeling good" (Belzak et al., 2017, p. 123 [15]). "Well-being [equates to] what is good for me" (Crisp, 2017) [21]. It "focuses on happiness and defines well-being in terms of pleasure attainment and pain avoidance" (Ryan \& Deci, 2001, p. 141 [22]). The current state of well-being is "the totality of one's hedonic moments" to date (Ryan \& Deci, 2001, p. 144 [22]). Some argue that achieving hedonic well-being (i.e., a life of gratification) depends on "selfishness, materialism, objectified sexuality, and ecological destruction" (Smith \& Reid, 2017, p. 4 [3]).

\subsection{Eudaimonic Well-being}

In contrast, the eudaimonic approach (OWB) focuses on "the processes which enable self-fulfilment, meaning and purpose [to realize] human potentiality" (Smith \& Reid, 2017, p. 4 [3]). Eudaimonic is Greek eu, "good" and daimon, "guardian, guide" (Harper, 2019 [20]). The term arises from what Aristotle called daimon, one's true self or true nature (Qizilbash, 2009 [18]; Smith \& Reid, 2017 [3]). While hedonic refers to the experiences of pleasure, eudaimonic pertains to the experiences of meaning. Hedonism is the pursuit of pleasure as a matter of principle. The eudaimonic approach refers both to contributing to the greater good and cultivating personal strengths by living a life of purpose (rather than instant gratification), vitality, self-actualization and integrity (McMahan \& Estes, 2011[16]; Ryan \& Deci, 2001 [22]). It envisions people achieving well-being by "pursuing meaningful, valuable and exemplary lives" (McMahan \& Estes, 2011, p. $105[16])$.

For clarification, the eudaimonic approach holds that although some desired outcomes may be pleasurable, they are not necessarily good for the person and thus will not promote well-being (McMahan \& Estes, 2011 [16]; Ryan \& Deci, 2001 [22]). With its OWB bend, the eudaimonic approach has also been criticized for being too paternalistic meaning those espousing it are trying to protect people for their own good possibly infringing on the latter's personal liberty (Crisp, 2017 [21]; Qizilbash, 2009 [18]; Smith \& Reid, 2017 [3]).

\section{Transdisciplinarity}

Reframing well-being in light of transdisciplinarity requires an explanation of trans, which is Latin for across, beyond, back and forth, zigzagging (lateral movements), moving through, passing beyond the limits to a new space (Harper, 2019 [20]; Nicolescu, 2002 [23]). As push back to the limitations of disciplinarity, multi and interdisciplinarity, transdisciplinarity was first coined as a term in 1972 (Apostel, Berger, Briggs \& Machaud, 1972 [24]; Bernstein, 2015 [25]). A world movement subsequently developed with two main schools of thought: Zurich and Nicolescuian (McGregor, 2015a [26]). Two other underutilized approaches were tendered by Erich Jantsch and Joseph Kockelmans (McGregor, 2010a [27]).

The Zurich school of thought emerged from a 2000 conference in Switzerland. Adherents to this approach assumed that science is the main research methodology but it has to be done differently within social constraints and with societal input (Klein et al., 2001) [28]. The approach informing this paper was initially formulated and advanced during the late eighties by Basarab Nicolescu (2002 [23], 2014 [29]). He views transdisciplinarity as a new methodology for creating knowledge (a companion to empirical, interpretive and critical methodologies) (see McGregor, 2018b) [30]. Nicolescu (2006) [31] characterized his approach as theoretical and the Zurich approach as phenomenological (i.e., application in context).

In more detail, after observing the world, Nicolescu concluded that there is both (a) too much fragmentation of knowledge (i.e., too many specializations in too many disconnected disciplines, over 8000) and (b) a strong penchant to privilege science over life-world knowing (Klein, 2014 [32]; Nicolescu, 2002 [23], 2014 [29]). Humanity faces a plethora of complex, vicious and aggressive psychological, social, political, economic and environmental messes: unsustainability, climate change, health pandemics, poverty, nonrenewable resource management, violence, uneven development, and uneven income and wealth distribution. Addressing these complex problems requires a unity of knowledge - a joining of disciplinary and other-sector knowledge (Nicolescu, 2002 [23], 2014 [29]).

Nicolescu thus called for the "fusion of knowledge and being" (2014, p. 212 [23]) referring, respectively, to objective science and subjective life (hearken objective and subjective well-being). With this in mind, 
Sue L. T. McGregor

Conceptualizing Trans Well-being within Transdisciplinarity

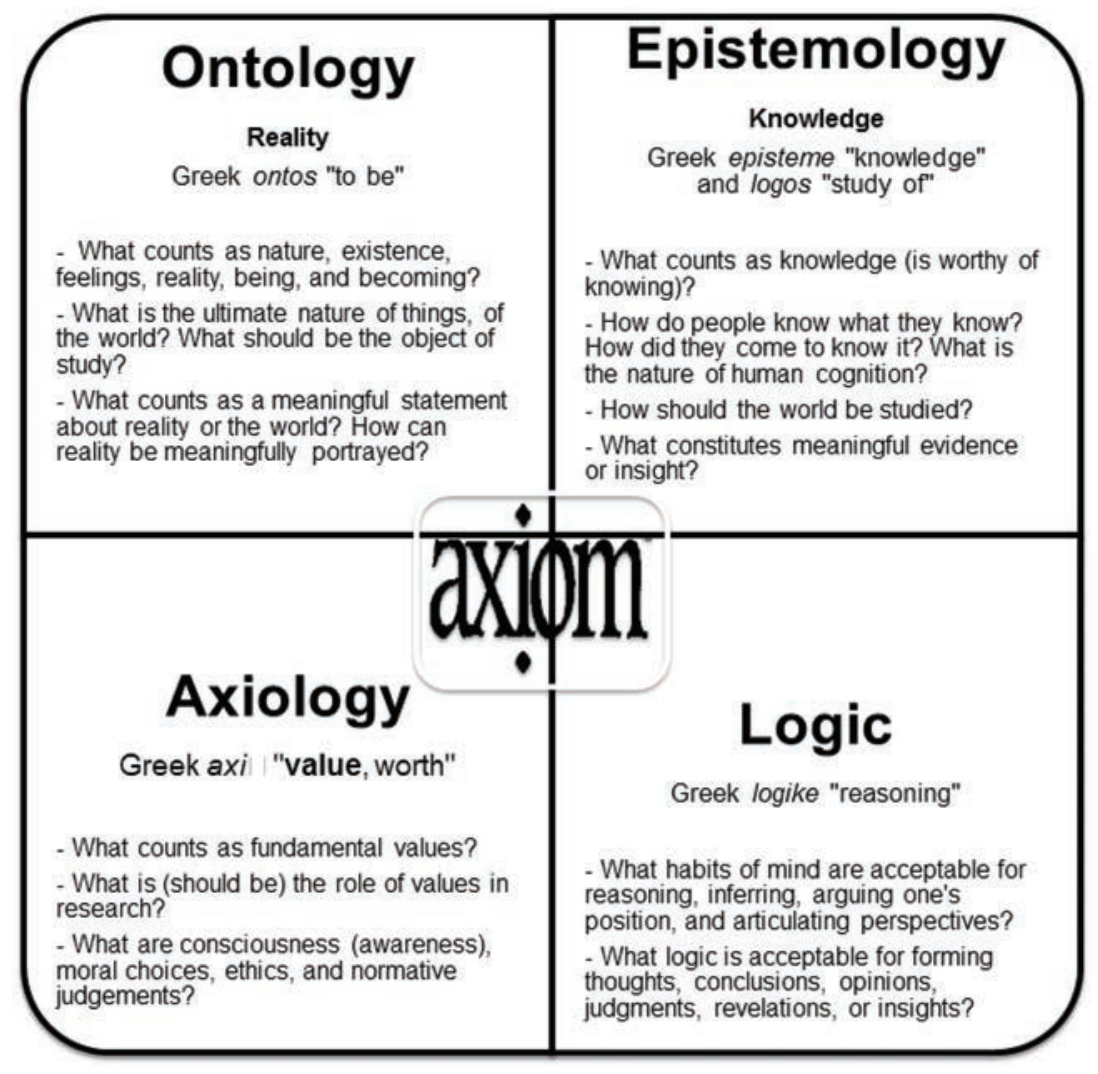

Figure 1: Nicolescuian transdisciplinary axioms.

he conceived of and 'worked out' (formulated) transdisciplinarity based on three conventional philosophical axioms: (a) ontology - what counts as reality, (b) epistemology - what counts as knowledge, and (c) logic habits of the mind considered acceptable when reasoning and drawing conclusions and insights (Nicolescu, 2002 [23]; Rohmann, 1999 [33]). Cicovacki (2004) [34] and McGregor (2011 [35], 2018b [30]) added the fourth axiom of axiology - the role of values in research - respecting that Nicolescu (2014) [29] asserted it is not necessary, to be discussed (see Figure 1).

\subsection{TD Ontology}

Nicolescu's (2002 [23], 2014 [29]) formulation of transdisciplinary ontology positioned it as multiple levels of Reality whose interface is mediated by the unifying force of the Hidden Third. These multiple Realities exist on two levels: (a) internal where human consciousness and perspectives flow (the TD-Subject) and (b) external where information flows (TD-Object). This collection of Realities (he capitalizes the word) corresponds to levels of understanding that deepen when reasoning moves from one level to and through another. Movement amongst these levels is lubricated with culture and art (aesthetics), religions and faiths, spiritualities, and the Sacred (Nicolescu, 2014 [29], 2016 [36]) (see Figures 2 and 3). Eric Reynolds creatively called these "spirit-opening modalities" because they enable knowledge and perspective integration to occur by serving as nonresistance-enabling forces (personal communication, August 15, 2018).

This conceptualization of reality eschews the Newtonian idea that there is one Reality out there waiting to be discovered using the scientific method. There are many, many Realities rife with resistance to each other but - to mock the Borg - resistance cannot be futile; contradictions and incongruities must be accommodated in order to create the TD knowledge required to address the messy complexities of the 


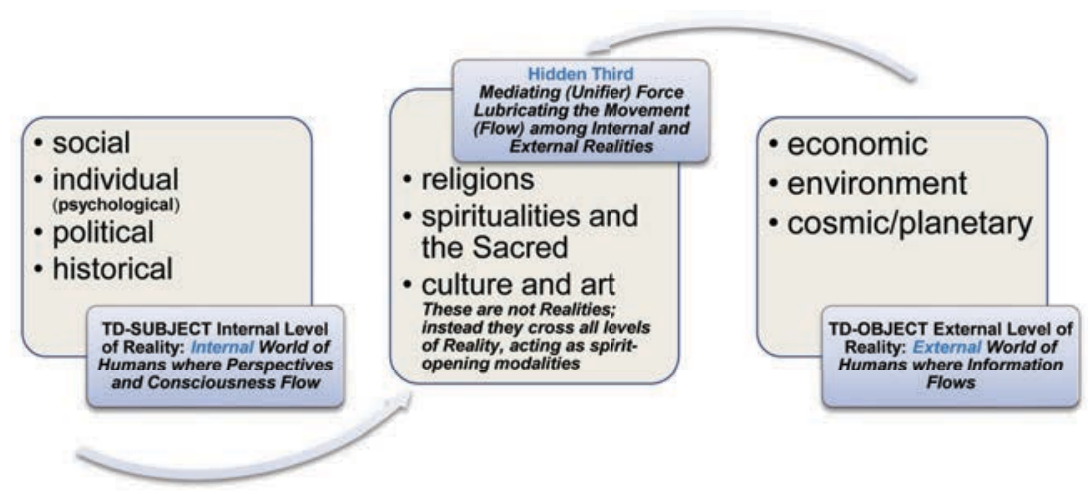

Figure 2: Nicolescuian transdisciplinary ontology.

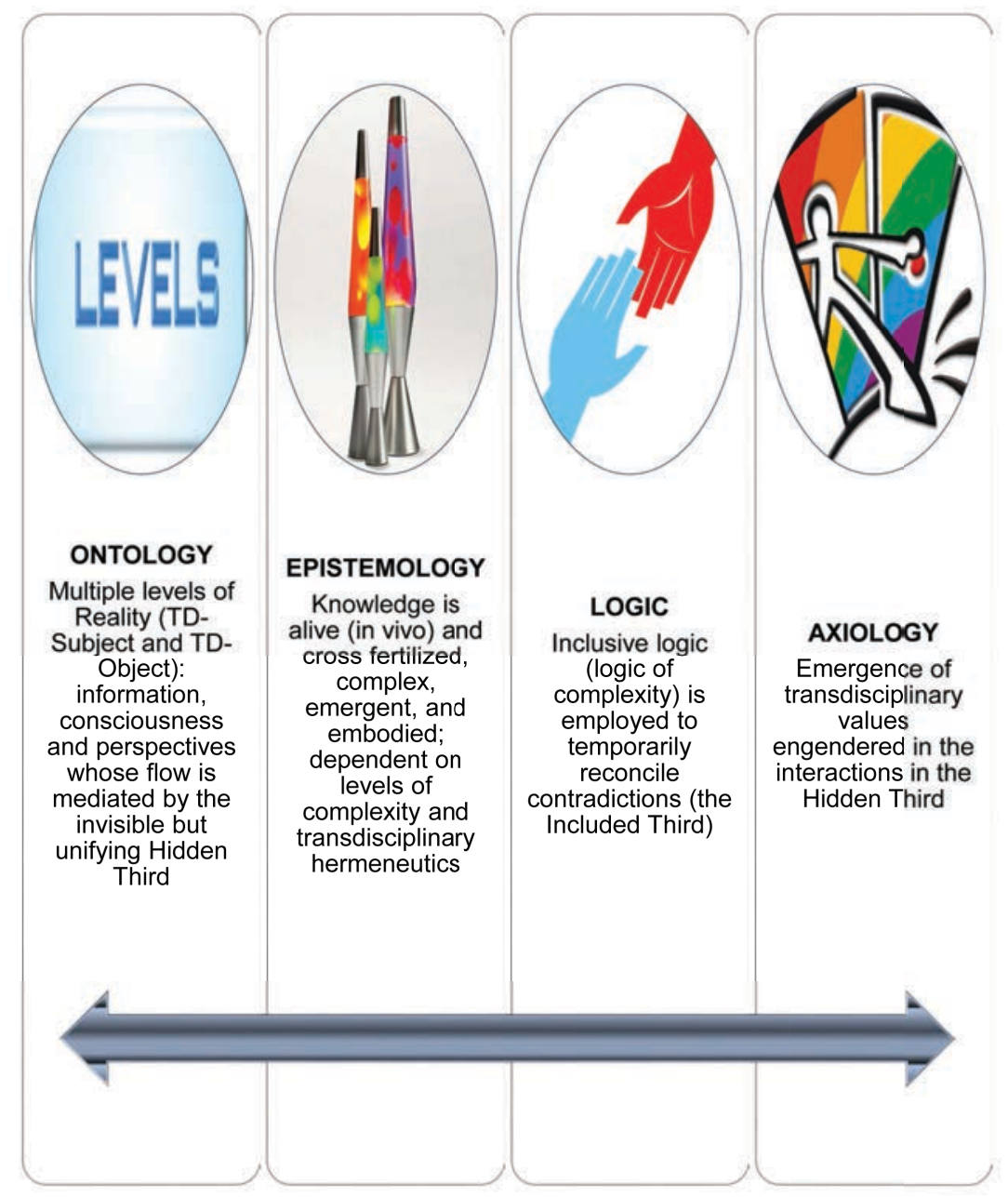

Figure 3: Nicolescuian Transdisciplinary Axioms.

world (McGregor, 2018b [30]; Nicolescu, 2014 [29]). 


\subsection{TD Epistemology}

Respecting this imperative (Star Trek pun continued), Nicolescuian epistemology (called complexity) understands knowledge to be alive and always in-formation (far beyond mere information); it is crossfertilized (many disciplines and sectors), complex (can adapt and self-organize), emergent (always coming into being) and embodied (made whole by and owned by everyone) (Nicolescu, 2006 [31]). All of the diverse people from the academy (university) and civil society (businesses, governments, citizens, and non-governmental organizations) co-create this knowledge, which they then co-own and shepherd (McGregor, 2018b [30]). McGregor (2015b) [37] used a lava lamp metaphor to explain the dynamics of this powerful fusion of intellects and horizons (perspectives) - this reconciliation of disparate mind sets so new TD knowledge can emerge.

Also TD epistemology encompasses transdisciplinary hermeneutics, which concerns what happens when people cross boundaries while engaging in TD work and how this happens. At issue is what conditions have to be in place for true understandings to emerge about each other and the emergent knowledge. When people's mental perceptions of something can be expanded, even transcended (to a new space), the unity of knowledge is more likely. The fusion of perceptions and prejudices leads to more powerful understandings of self, others and the emergent TD knowledge (Nicolescu, 2014 [29]; van Breda, 2007 [38]).

\subsection{TD Logic}

Nicolescu formulated that TD knowledge creation happens through the use of inclusive logic, which means nothing is excluded even if it is antagonistic, contradictory and tension forming. All input has the potential to lead to new knowledge with people meeting in the fecund space (i.e., fertile middle ground) between the academy and civil society to share and co-create it. Nicolescu (2002) [23] based his formulation of this space on the quantum notion of a vacuum, which is not empty but at its lowest energy level, ripe with potential. In this included middle (e.g., the undulating floor of the lava lamp), diverse perspectives can temporarily be set aside so people can become open to others' ideas and viewpoints leading to the emergence and creation of something new.

They do so by employing the logic of complexity leading to complex TD knowledge (Nicolescu, 2014) [29]. Complexity is Latin complexus, "that which is woven together" (Harper, 2019) [20]. The opposite of complex is not simplicity but that which is not woven; it is independent (Alvira, 2014) [39]. Complexity logic lets people cross and connect different ways of knowing in creative and coherent ways (Nicolescu, 2014) [29]. Combined with inclusive logic, it is a powerful way to create new TD knowledge.

\subsection{TD Axiology}

Axiologically, this emergent TD knowledge creation process entails both the respect and management of actors' values as well as the emergence of new transdisciplinary values that did not exist before. Nicolescu believed that a separate axiology axiom is not necessary because values derive (originate) from epistemology, ontology and logic. TD values arise from, are engendered in, the interactive region of the Hidden Third (McGregor, 2018b [30]; Nicolescu, 2002 [23], 2010a [40]). He further argued that these TD values matter more than each individual's value schemata in place when entering and sustaining activities during TD knowledge creation. He claimed that these derived "values are engendered by Trans-Reality. They are not human-made" (Basarab Nicolescu, personal communication, June 9, 2010). They arise from the primordial soup so to speak.

In contrast, McGregor (2009) [41]posited that people's value schemas matter and cannot be dismissed; instead, initial value positions can shift over time during people's engagement in the included middle thereby creating the "potential to converge into an integral collection of values that privilege transdisciplinary tenets." It is called integral because what emerges from this rich interaction 'is what it is' because this particular constellation of TD values jelled. If something is integral, it is absolutely essential and indispensable - the new whole would not 'be what it is' without it (McGregor, 2018a) [42]. TD values, in effect, transcend individual values moving to a unique arrangement that reflects the dynamics of a 
particular problem solving engagement. This unified knowledge becomes part of the world's knowledge base for all to use.

\section{Alternative Perspectives of Well-being}

Much like Nicolescu (2002) [23] took issue with the fragmented subject and object, Smith and Reid (2017) [3] urged well-being scholars to move beyond the prevailing dichotomy between subjective (hedonic) and objective (eudaimonic) well-being. This transition will be especially necessary if people choose to align well-being with transdisciplinarity, which, in summary, encompasses complexity, emergence, multiple perspectives, aliveness, and openness to new ways of thinking. It requires the integration of human consciousness and perspectives with external information - the soft with the hard. What emerges must be owned and stewarded by everyone involved. Transdisciplinarity embraces inclusiveness, joint collaboration and inventiveness, intellectual and perspective fusion, modes of reasoning (logic) that accommodate weaving together disparate viewpoints, and the birth of TD-steeped values.

In the TD context, the concept of well-being has to broaden and deepen. Focusing on individual states of being (whether hedonic or eudaimonic) is not enough when so many actors are intricately and integrally involved in the fluid and emergent process of addressing complex issues in search of plausible solutions and implementing and living with those solutions so humanity's well-being is enhanced. It is a given that human well-being is a central feature of the dynamics of complex systems and interactions; hence, well-being must remain a central aspect of addressing complex problems (Apgar et al., 2009) [2].

By association, well-being scholars need to respect "people in their complexity, in their social and historical contexts" (Gasper, 2004, p. 30 [10]). Well-being should be conceived as "an open-ended phenomenon [that resists] the imposition of pre-established categories" (Smith \& Reid, 2017, p. 11 [3]). Such an approach would "offer an appreciation for the emergent complexities of human-ecological relations" (Smith \& Reid, 2017, p. 11 [3]). Indeed, McIntyre-Mills (2014) [5] claimed that instead of associating well-being with individual or aggregate economic prosperity, well-being scholars should embrace the idea that "wellbeing rests on mindfulness of our relationships with others and with the environment, not on status or ability to live [consumerism-fuelled] lifestyles of our own choosing" (p. 75).

Others concur, agreeing to the need to reframe well-being as 'being with other' as well as with the environment (Gough \& McGregor, 2007 [43]; Millennium Ecosystem Assessment, 2005 [44]). Armitage and colleagues defined well-being as "a state of being with others and the natural environment that arises where human needs are met, where individuals and groups can act meaningfully to pursue their goals, and where they are satisfied with their way of life" (Armitage, Béné, Charles, Johnson, \& Allison, 2012, p. 3 [45]). White (2017) [46] also framed well-being as arising through and with others. She claimed that relationships are "intrinsic to the constitution and experience of well-being" (White, 2017, p. 128 [46]); well-being is dependent on relationships, which are essential to the quality and character of each person's well-being.

The following text identifies and explains four alternative conceptualizations of well-being and juxtaposes them against transdisciplinarity: social conception, self-transcendence, intra-action, and relational wellbeing (see Figure 4). These nascent constructs were culled from the literature both by using Boolean search techniques based on the concepts of well-being (wellbeing) and transdisciplinarity and following leads emergent from particular articles. The search process was especially inspired by the early find of Smith and Reid's (2017) [3] article titled Which 'being' in well-being? This ontological play on words resonated with Nicolescu's (2002) [23] especially formulated ontology (concerned with Reality, coming into being, becoming, existing). These four approaches represent the only ones found in the search process using the parameters explained herein.

\subsection{Social Conception of Well-being}

Armitage et al. (2012) [45] envisioned well-being as both a process and an outcome, which is a shift from conventionally viewing well-being as a state of being (i.e., just the outcome). They created a social 
Sue L. T. McGregor

Conceptualizing Trans Well-being within Transdisciplinarity

\begin{tabular}{|c|c|c|c|}
\hline Social Conception & Self-transcendent & Intra-active & Relational \\
\hline $\begin{array}{l}\text { Well-being is } \\
\text { both outcome } \\
\text { (state) and } \\
\text { process } \\
\text { Well-being is a } \\
\text { state of being } \\
\text { with others } \\
\text { made possible } \\
\text { because of the } \\
\text { processual } \\
\text { interface of } \\
\text { material, } \\
\text { relational, and } \\
\text { subjective } \\
\text { components }\end{array}$ & $\begin{array}{l}\text { A higher range } \\
\text { of well-being } \\
\text { exists when } \\
\text { people are } \\
\text { open and have } \\
\text { the chance to } \\
\text { transcend } \\
\text { beyond their } \\
\text { psyche to } \\
\text { another space } \\
\text { or level after } \\
\text { experiencing } \\
\text { 'the } \\
\text { transcendent' } \\
\text { (different from } \\
\text { normal } \\
\text { experiences) } \\
\text { Well-being is } \\
\text { an epistemic } \\
\text { self-discovery } \\
\text { not of one's } \\
\text { own volition } \\
\text { (aha! awe- } \\
\text { inspiring } \\
\text { moments) }\end{array}$ & $\begin{array}{l}\text { A process- } \\
\text { oriented } \\
\text { approach } \\
\text { concerned at } \\
\text { the micro level } \\
\text { with how } \\
\text { entities and } \\
\text { relationships } \\
\text { come into } \\
\text { existence } \\
\text { relative to the } \\
\text { transient, } \\
\text { transpersonal, } \\
\text { and contextual } \\
\text { nature of well- } \\
\text { being } \\
\text { World is } \\
\text { considered to } \\
\text { be in perpetual } \\
\text { process of } \\
\text { becoming so } \\
\text { well-being also } \\
\text { has to be } \\
\text { always } \\
\text { becoming and } \\
\text { unfolding }\end{array}$ & $\begin{array}{l}\text { Well-being is } \\
\text { an emergent } \\
\text { process by } \\
\text { which } \\
\text { something } \\
\text { appears over } \\
\text { time through } \\
\text { the interplay of } \\
\text { relational self } \\
\text { (always in } \\
\text { relationships), } \\
\text { societal } \\
\text { structures, and } \\
\text { the natural } \\
\text { environment } \\
\text { Well-being is } \\
\text { situated and } \\
\text { emergent } \\
\text { Relationality is } \\
\text { generative } \\
\text { meaning } \\
\text { relations shape } \\
\text { well-being } \\
\text { Well-being } \\
\text { arises through } \\
\text { and with others }\end{array}$ \\
\hline
\end{tabular}

Figure 4: Alternative conceptualizations of well-being.

conception of well-being by nesting individual basic human needs within social-psychological and cultural needs. Understanding the process of well-being (i.e., a series of steps toward a particular end or outcome) entails viewing it as human agency and capabilities that "emerge [at] the interplay of the objective (e.g., people's circumstances shaped by material and relational dimensions) and the subjective (e.g., values and perceptions)" (Armitage et al., 2012, p. 4 [45]). White (2017) [46] also positioned well-being as "anchored in material and relational contexts" (p. 128). In short, well-being emerges during the interplay of the subjective and objective much like TD knowledge emerges from the interplay of TD-subject and TD-object (see Figure 2).

In more detail, Armitage et al. (2012) [45] explained that the material component of social-focused well-being encompasses both physical and financial assets considered essential to well-being: income, health, assets, wealth, and public and private services. The relational component focuses on social and collective interactions, reciprocity, and a sense of self-identity in concert with community connections all shaped by state and societal structures. The subjective component includes values, beliefs, norms, perceptions, and notions of self - "a sense of . . . contentment with [their] "way of life"' (p.4). Armitage et al. (2012) [45] believed that knowledge of the processes involved in three dimensions coming together to create the outcome of "a "life well lived"' (p. 4) is a valuable way to conceptualize well-being. Put simply, a social focus respects that "well-being is a state of being with others"' (p. 4).

Transdisciplinarity is all about social connections, interactions, processes and emergence (McGregor, 2018b) [30]. Conceptualizing well-being through a social lens, which is concerned with basic human needs, cultural needs and social-psychological needs, provides a way to deal with material realities, relational dynamics, and values, beliefs and norms. Transdisciplinarity cares for material circumstances, relationships and values all of which shape problem posing, addressing and solving. Considering how the needs of people, society and culture affect 'being with others' is a valuable shift in how to view well-being. From a TD 
perspective, solving complex problems requires entering and working within the fertile middle ground where mindsets are temporarily set aside so all voices can be heard and integrated using inclusive and complexity logics. The resultant well-being that emerges would be a new "state of being with others" that arose from a rich process; well-being is both outcome and process (Armitage et al., 2012, p. 4 [45]).

\subsection{Self-transcendent Well-being}

Transdisciplinary knowledge is alive and always in formation, changing with insights, innovations and inspiration (Nicolescu, 2014) [29]. In their discussion of whether inspiration falls under the hedonic or eudaimonic well-being traditions, Belzak et al. (2017) [15] created the new concept of self-transcendent well-being. Self-transcendent people are inclined to reach out beyond themselves. They have "the capacity to expand self-boundaries intrapersonally (toward greater awareness of one's philosophy, values, and dreams), interpersonally (to relate to others and one's environment), temporally (to integrate one's past and future in a way that has meaning for the present), and transpersonally (to connect with dimensions beyond the typically discernible world)" (Reed, 2003, p. 147 [47]). This is possible because these people tend to be open to experiences and exhibit energetic, powerful behaviour (De Fruyt, Van De Wiele, \& Van Heeringen, 2000) [48].

In practice, this form of well-being exists when people, who are open to experience, actually experience revelatory encounters with the transcendent (something that is apart from normal human experiences) evident in a-ah, light-bulb, awe-inspiring life moments. Self-transcendent encounters help people to move beyond their conscious self to a new place of insight and inspiration (Belzak et al., 2017) [15]. This is possible because they have been open to and actually encountered an experience or phenomenon that pushed them even beyond self-actualization to a place where they are transcenders, "instruments of the transpersonal" (Maslow, 1993, p. 282 [49]). To be discussed, transpersonal refers to people stepping outside their personality, beyond their own psyche, to a new space (Kelly, 2005) [50].

Self-transcendent well-being is "a 'higher' range of well-being experiences" (Huta \& Ryan, 2010, p. 739 [51]). It is "triggered by illumination," which is possible when people are "open to aesthetics, absorption [and] self-forgetfulness" (Belzak et al., 2017, p. 135 [15]). This is exactly the type of well-being that needs to be engendered when people enter the fertile middle ground to engage in TD work. They need to become open to others' world views and perspectives, an openness that is lubricated by the spirit-opening modalities of aesthetics enabling people to become absorbed in the emergent TD knowledge-creation process. They would not lose themselves but find themselves.

This is different from eudaimonic well-being, which is a "kind of volitional self-expression" (Belzak et al., 2017, p. 135 [15]) (i.e., purposeful expression of will). Instead, self-transcendent well-being is an "epistemic self-discovery" (p. 135) (i.e., new insights into self). This resonates perfectly with TD epistemology and ontology wherein new knowledge (episteme) emerges from employing inclusive logic in the lubricating and illuminating Hidden Third (the transcendent process of becoming) (Nicolescu, 2002) [23].

\subsection{Intra-active Well-being}

Transdisciplinary work is dependent on interactions among people during the process of co-creating TD knowledge (Nicolescu, 2002) [23]. Accordingly, Barad's (2003 [52], 2007 [53]) quantum notion of intraactive, employed by Smith and Reid (2017) [3] to conceptualize intra-active well-being, opens interesting ontological doors for TD work. Both Nicolescuian TD and Barad's intra-active concept are grounded in some combination of the new sciences of complexity, chaos and quantum physics (e.g., embeddedness, emergence, entanglement).

Inter means between and among and intra means within and inside (Harper, 2019). Barad (2003 [52], 2007 [53]) believed another concept was needed beyond interaction, which assumes that entities pre-exist and can relate. Barad was interested in what is involved in the process of these entities coming into existence or materializing in the first place. Concerned with "the materialization of all bodies - 'human and nonhuman"' (2003, p. 810 [52]), Barad argued that "all phenomena are ontologically primitive relations [; 
Sue L. T. McGregor

Conceptualizing Trans Well-being within Transdisciplinarity

that is, there are no independent entities only] entities within relations" (2003, p. 815 [52]). Similarity, Nicolescuian ontology assumes that all levels of reality are what they are because they are in relation with each other (Nicolescu, 2014 [29], 2016 [36]).

The intra-action concept (i.e., what happens within) concerns how relations and entities (e.g., knowledge) materialize; ontologically ignoring how these relations 'come to be' means people "will miss all of the crucial intra-actions among these factors" (Barad, 2003, p. 810 [52]). Inspired by Barad's (2003 [52], 2007 [53]) focus on, what could be called, the imperceptible but very real intra context of entities and relationships, Smith and Reid's [3] conceptualization of intra-active well-being "attends to the more transient, transpersonal and contextual aspects of wellbeing" (2017, p. 1). This attention to imperceptible but influential processes resonates with TD work.

Respectively, people who are engaged in TD work are transient - they have a foot in their academic home while roaming the connections available in a network of relationships and contexts, iteratively staying in each place for short periods of time (Smith, 2003) [54]. TD work is transpersonal meaning people transcend (i.e., climb beyond existing limits) their individuality and personality so they can engage in complexity work with others (Kelly, 2005) [50]. Although TD is all about context, Smith and Reid (2017) [3] (geographers) maintained that well-being scholars have neglected to take into account the impact of context, space and place on the conditions that shape well-being.

From a transdisciplinary standpoint, intra-active well-being is a very useful ontological acknowledgement of the dynamics behind, between and beyond relationships and new knowledge becoming a reality within the included middle while disparate people interact. The micro, intra dynamics of the formation of these emergent entities (i.e., relationships and knowledge) is an intriguing approach to well-being within transdisciplinarity. Said another way, well-being comes into being during TD work and there is a rich, micro process behind this phenomenon. In effect, well-being may be better conceived "as relational practices rather than [a] stable foundation of . . . life" (Smith \& Reid, 2017, p. 10 [3]).

To reiterate, Smith and Reid (2017) [3] created intra-active well-being as a way to deal with the more process-oriented transient, transpersonal and contextual aspects of well-being that are shaped by intra-active forces; this takes well-being far beyond a static 'state of being.' Instead, the formation of well-being is contingent upon and inseparable from the micro context within which it is embedded and entangled (Barad, 2003) [52]. The well-being as intra-active approach (i.e., well-being is "never stable, never the same") sheds light on the dynamics often concealed when well-being is defined as already existing "as stable and measurable" in a person's mind (Smith \& Reid, 2017, p. 4 [3]). Similarly, TD knowledge is alive, never the same, always evolving (Nicolescu, 2002) [23] making these two approaches quite compatible.

Smith and Reid (2017) [3] also ingeniously referred to the world as being complex and full with this "fullness in a constant process of becoming" (p. 12); by association, they rationalized that a vibrant conceptualization of well-being is warranted, one that views it as a fluid process. This is especially relevant within the context of transdisciplinarity where knowledge is deemed alive and the world's future depends on the fusion of disciplinary and life-world knowledge so the world can remain complex and always becoming (McGregor, 2018b [30]; Nicolescu, 2002 [23]). Well-being as intra-active scaffolds this basic transdisciplinary premise in that it respects the micro processes behind the materialization of entities, both human and nonhuman (e.g., knowledge). To reiterate, this construct intimates that 'well-being comes into being' during TD work.

Finally, TD work also involves many different people temporarily letting a part of themselves go to make room for others' perspectives (McGregor, 2018b) [30]. This eventuality benefits from a conceptualization of well-being that presumes people are "part of the world becoming [which involves] the unfolding of well-being" (Smith \& Reid, 2017, p. 14 [3]). In fact, Gasper (2004) [10] used the term "well-becoming" to accommodate the idea that people "must be created, formed, emerge [so they can] exist in time" (p. 6.). To complete the circle, their well-being is linked to well-becoming and well-dying. Smith and Reid's (2017) [3] conceptualization of intra-active well-being draws on concepts that are the bedrock of transdisciplinarity: letting go (mini dying), unfolding, becoming, and emerging along with embeddedness, processes, and complex dynamics. 


\subsection{Relational Well-being}

Well-being is a process and has a relational dimension (Armitage et al., 2012) [45]. In that spirit, relational well-being concerns "the terms and qualities of relationships" while individual or personal well-being refers to how "well-being is thought [about], felt and experienced" (White, 2017, p. 128 [46]). Important to Nicolescu (2002 [23], 2014 [29]), "ground[ing] wellbeing in a relational ontology ... can challenge discourses that result ... in the fragmentation of the self" (White, 2017, p. 129 [46]). Theorized and developed by White (2017), relational well-being is grounded in three factors. "Relational selves, societal structures and the natural environment [each has] some relative autonomy with its own structures and processes [while concurrently] being interdependent and in tension with each other" (White, 2017, p. 131 [46]).

In more detail, the term relational self refers to people's inclination to define their own personal well-being from "the sense of being in relationship" with others (White, 2017, p. 130 [46]). Reciprocity is key with the imperative being to sustain relationships instead of worrying about who will benefit, how or when. Although these are unknown, people are confident that help and support will be forthcoming because the relationships have been nurtured and sustained (White, 2017) [46].

White's (2017) [46] second notion of societal structures involves respecting the power inherent in having established (solid) structures instead of privileging the tenets of "openness, flow and flexibility," which intimates fluid structures (p. 130). People pattern their life narratives through these societal structures so the former "should not be under emphasized" (p. 130) [46]. Third, relational well-being includes the natural environment, the local context, and the larger concept of place. She [46] maintained that the rhythms, flows, processes and tipping points of nature have to be accorded due respect because they influence human well-being as well as humans' relationship with nature.

White (2017) [46] concluded that relationality is central to well-being. Relationality is generative, meaning it is capable of generating and producing something. With this in mind, she framed relational well-being as an emergent process, "something that happens [emphasis added] in and over time through the dynamic interplay of personal, societal and environmental structures and processes" (p. 133 [46]). She [46] believed that relations come first, not people; relations shape well-being. Accordingly, well-being is not always quantifiable, either there or not. Instead, it is "situated and emergent" (Smith \& Reid, 2017, p. 11 [3]). Likewise, TD knowledge is situated and emergent suggesting a plausible alignment between relational well-being and transdisciplinarity.

\section{Prototypical Well-being}

As discussed earlier, the classical approach to defining the concept of well-being relies on researchers identifying a collection (list) of necessary and sufficient features that all have to be present in order to measure or experience well-being (Hone et al., 2015) [11]. This section elaborates on Rosch's (1975) [55] challenge to this assumption. She [55] suggested that the concept of well-being is not generic; rather, it is a prototype developed and used by each person (it may or may not align with scholars' conceptualizations of well-being). Given that TD work depends on a fusion of disciplinary and lay knowledge (Nicolescu, 2002) [23], lay notions of well-being deserve attention here.

A prototype is the preliminary form from which other forms are developed. It is also considered to be a typical example of something, ideally a good example. In the field of innovation and design, a prototype is built to test a concept; it is a fully working model. A prototype approach to well-being involves people categorizing things in terms of their similarity to a good example of well-being. In contrast, a classical approach to well-being assumes there are essential elements in a list that must be present for well-being (Rosch, 1975) [55].

Rosch [55] further theorized that in order for people to have a prototype of well-being, they must be able to (a) compile a list of dimensions or features of well-being, (b) rate the centrality of (i.e., agree upon) each feature relative to how it helps them understand well-being, and (c) illustrate that this centrality affected how they think about well-being (i.e., their cognition). Rating each feature contributes to the creation of an internal structure of well-being in their mind, a prototype they can then turn to when needed 
Sue L. T. McGregor

Conceptualizing Trans Well-being within Transdisciplinarity

(Rosch, 1975) [55]. They do not rely on third-person conceptualizations of what 'being and living well' look like (i.e., eudaimonic); instead, they make up their own.

Rosch (1975) [55] further explained that, from a prototype approach, the well-being concept has both content and a structure. Content pertains to, what well-being scholars often call, dimensions or features of well-being such as economic, social, emotional, political, cultural, environmental, spiritual, and existential (see McGregor \& Goldsmith, 1998) [56]. Structure refers to whether the person deems specific dimensions as essential (i.e., central) or less essential (peripheral) to their understanding of well-being (Rosch, 1975) $[55]$.

In more detail, central features are strongly associated with the concept while peripheral ones are not. The latter are of secondary importance and less essential to one's understanding of what constitutes well-being; one's are not an integral part of the concept but they do inform it (Rosch, 1975) [55]. The prototype approach accepts that for well-being to be experienced, the features deemed by that person to be central (i.e., the core of the prototype) must be there rather than all critical features identified in an arbitrary list having to be there. The prototype approach allows for 'degrees of well-being' rather than an all-in approach (Kearns \& Fincham, 2004) [57].

Why does this matter? Hone et al. (2015) [11] opined that the proliferation of so many different conceptual definitions of wellbeing supports their assertion that there are lay prototype structures. Put simply, lack of researcher agreement of what constitutes well-being (i.e., what should be in the list) indicates that some features are central and others are peripheral with this scenario called prototypical for each person rather than generic or theoretical. To illustrate, Kearns and Fincham (2004) [57] showed that each person has a prototype of the concept of forgiveness that she or he can activate and use; this lay prototype may or may not align with theories of forgiveness. They confirmed that this finding also holds for the concepts of love and commitment with Hone et al. (2015) [57] intimating the same for well-being.

Each person's well-being prototype typically has both central and less-essential features; it is prototypical (unique) for that person. By "activating the prototype," people can assess their well-being or that of others (Kearns \& Fincham, 2004, p. 851 [57]). Following their [57] lead for the forgiveness concept, people are encouraged to heed prototypical lay conceptions of well-being because the latter may augment and advance well-being conceptualization. A prototypical approach has merit. If, as transdisciplinarity assumes, a diverse collection of people is coming together to address and hopefully solve complex societal problems, a diverse collection of lay perspectives on well-being makes sense with prototypical well-being augmenting, maybe transcending, conventional and alternative conceptualizations.

\section{Discussion and Conclusions}

After explaining the conventional approaches to well-being, four alternative conceptualizations were profiled and juxtaposed against transdisciplinarity: social conception, self-transcendent, intra-active, and relational (see Figure 4). After careful consideration, the key takeaway of 'What might well-being look like within transdisciplinarity?' is that well-being is emergent and relational; it is about being and becoming with others. This analytical insight prompted the new term trans well-being (not to be confused with the well-being of trans people, Ashley, 2018 [58]).

A working definition of trans well-being embodies specific aspects of the four approaches that nourish the new definition. These include a sense of well-being that transcends conventional hedonic (SWB) and eudaimonic (OWB) approaches, which focus respectively on self-assessment or third-party assessment but not conjoined creation and assessment of well-being by both researchers and lay people (prototypical). Dichotomizing subjective and objective well-being makes no sense when the entire premise of transdisciplinarity is to unite the TD subject with the TD object (Nicolescu, 2002 [23]). Trans well-being would thus respect the axiomatic tenets of Nicolescuian transdisciplinarity (see Figures 2 and 3). It would especially focus on relations, processes, context, transcendence, and being and becoming.

The first four factors are key tenets of Nicolescuian transdisciplinarity (McGregor, 2018b [30]; Nicolescu, 2002 [23]) and reinforce the notion of augmenting TD with alternative conceptualizations of well-being. 
Regarding being and becoming, Smith and Reid [3] posed the existential "unspoken question of which 'being' is implied when researching well-'being"' (2017, p. 2). Gasper (2004) [10] raised a parallel concern when commenting that "too much work on well-being has been based on insufficient evidence and theory about be-ing" (p. 29). Given that ontology is the most contested TD axiom (Nicolescu, 2010b) [59], the ontological observation that the being part of well-being has been shortchanged is even more compelling.

Fortunately, a cursory analysis revealed that alternative well-being scholars are respecting the call to focus on the dynamic, processual being and becoming part of well-being. Specifically, focusing on italicized entries in Figure 4, trans well-being, relative to transdisciplinarity, would be a process that is situated, contextual and emergent. It would always be unfolding and becoming, arising with and through others. Trans well-being would be a state of being with others (and the environment) and might even be a form of epistemic self-discovery (insights into psyche and self). These suppositions inspire further ontological and theoretical investigation to generate insights that could help advance "transdisciplinarity and a reframed approach to wellbeing" (McIntyre-Mills, 2014, p. 75 [5]).

In closing, transdisciplinarity is concerned with how to "better understand the world, the contemporary human situation, and the meaning of human life" (McGregor, 2010a) [27]. Reversed, this equates to eudaimonic (meaning), hedonic (current state) and trans-well being (unified understandings via melding of subjective and objective). This conceptual research mapped the nascent research terrain evolving around alternative conceptualizations of well-being and better defined the concept in the context of transdisciplinarity (Rocco \& Plakhotnik, 2009) [6]. Alternative conceptualizations of well-being were shown to positively align with transdisciplinarity's four axioms (see Figure 3). This conceptual alignment proves promising for future research and practice. Trans well-being would involve a shift from viewing well-being as a state of being to a process of being with others in perpetual evolution.

Funding: This research received no external funding.

Conflicts of Interest: The author declares no conflict of interest.

\section{References}

[1] McGregor, S. L. T. (2016). Transdisciplinary professionalism for home economics. International Journal of Home Economics, 9(1), 54-71.

[2] Apgar, J. M., Argumedo, A., \& Allen, W. (2009). Building transdisciplinarity for managing complexity: Lessons from Indigenous practice. International Journal of Interdisciplinary Social Sciences, 4(5), 255-270.

[3] Smith, T. S. J., \& Reid, L. (2017). Which 'being' in wellbeing? Ontology, wellness and the geographies of happiness. Progress in Human Geography, 20(10), 1-23. doi:10.1177/0309132517717100

[4] Efthimiou, O. (2017). Understanding heroism: Transdisciplinary perspectives (Doctoral thesis, Murdoch University, Perth, Australia). Retrieved from https://pdfs.semanticscholar.org/b239/ acec8941df60eb990710826eb8476dd51415.pdf

[5] McIntyre-Mills, J. (2014). Transformation from Wall Street to wellbeing. New York, NY: Springer.

[6] Rocco, T. S., \& Plakhotnik, M. S. (2009). Literature reviews, conceptual frameworks, and theoretical frameworks: Terms, functions, and distinctions. Human Resource Development Review, 8(1), 120130.

[7] Smithey Fulmer, I. (2012). Editor's comments: The craft of writing theory articles: Variety and similarity to AMR. Academy of Management Review, 37(3), 327-331.

[8] Mitstifer, D. I. (1996). Preface. In Toward a theory of family well-being (p. v). East Lansing, MI: Kappa Omicron $\mathrm{Nu}$.

[9] Grammarist. (2013). Well-being vs. wellbeing. Retrieved from https://grammarist.com/spelling/well-beingwellbeing/

[10] Gasper, D. (2004). Human well-being: Concepts and conceptualizations [UNUWIDER Discussion Paper No. 2004/06]. Helsinki, Finland: United Nations University World Institute for Development Economics Research. Retrieved from https://www.econstor.eu/bitstream/10419/52803/1/38914200X.pdf 
Sue L. T. McGregor

Conceptualizing Trans Well-being within Transdisciplinarity

[11] Hone, L. C., Schofield, G., \& Jardin, A. (2015). Conceptualizations of wellbeing: Insights from a prototype analysis on New Zealand workers. New Zealand Journal of Human Resources Management, 15(2), 97-118.

[12] McGregor, S. L. T. (2010b). Well-being, wellness and basic human needs in home economics [McGregor Monograph Series No. 201003]. Seabright, NS: McGregor Consulting Group. Retrieved from http://consultmcgregor.com/documents/publications/well-being_wellness_and_basic_human_needs_in home_economics.pdf

[13] King, P. (2007). The concept of well-being and its application in a study of aging in Aotearoa New Zealand [EWAS Working Paper Series No. 8]. Lower Hutt, NZ: Family Center.

[14] Marshall, V., McMullin, J., Ballantyne, P., Daciuk, J., \& Wigdor, B. (1995). Contributions to independence over the adult life course. Toronto, ON: University of Toronto, Centre for Studies of Aging.

[15] Belzak, W. C. M., Thrash, T. M., Sim, Y. Y., \& Wadsworth, L. M. (2017). Beyond hedonic and eudaimonic well-being: Inspiration and the self-transcendence tradition. In M. D. Robinson \& M. Eid (Eds.), The happy mind: Cognitive contributions to well-being (pp. 117-138). New York, NY: Springer International.

[16] McMahan, E. A., \& Estes, D. (2011). Hedonic versus eudaimonic conceptions of well-being: Evidence of differential associations with self-reported well-being. Social Indicators Research, 103(1), 93-108.

[17] Western, M., \& Tomaszewski, W. (2016). Subjective wellbeing, objective wellbeing and inequality in Australia. PLoS One, 11(10), e0163345. doi:10.1371/journal.pone.0163345

[18] Qizilbash, M. (2009). Well-being, preference formation and the danger of paternalism [Working papers on economics and evolution, No. 0918]. Jena, Germany: Max-Planck-Institute of Economics.

[19] Sianf. (2011, February 24). Objective vs. subjective well-being [Web log post]. Retrieved from https://webarchive.nationalarchives.gov.uk/20110422105054/http:well-being.dxwconsult.com/ 2011/02/24/objective-vs-subjective-well-being/

[20] Harper, D. (2019). Online etymology dictionary. Lancaster, PA: Author. Retrieved from https://www.etymonline.com/

[21] Crisp, R. (2017). Well-being. In E. N. Zalta (Ed.), Stanford encyclopedia of philosophy. Stanford, CA: Stanford University. Retrieved from https://plato.stanford.edu/entries/well-being/\#Hed

[22] Ryan, R. M., \& Deci, E. L. (2001). On happiness and human potentials: A review of research on hedonic and eudaimonic well-being. Annual Review of Psychology, 52, 141166.

[23] Nicolescu, B. (2002). Manifesto of transdisciplinarity. Albany, NY: SUNY Press.

[24] Apostel, L., Berger, S., Briggs., \& Machaud, G. (Eds). (1972). Interdisciplinarity, problems of teaching and research in universities. Paris, France: OECD.

[25] Bernstein, J. H. (2015). Transdisciplinarity: A review of its origins, development, and current issues. Journal of Research Practice, 11(1), Article R1, http://jrp.icaap.org/index.php/jrp/article/view/510 $/ 412$

[26] McGregor, S. L. T. (2015a). The Nicolescuian and Zurich approaches to transdisciplinarity. Integral Leadership Review, 15(3), http://integralleadershipreview.com/13135-616-the-nicolescuian-and-zurich-approaches-totransdisciplinarity/

[27] McGregor, S. L. T. (2010a). Historical notions of transdisciplinarity in home economics. KON FORUM, 16(2), http://www.kon.org/archives/forum/16-2/mcgregor.html

[28] Klein, J. T., Grossenbacher-Mansuy, W., Häberli, R., Bill, A., Scholz, R., \& Welti, M. (Eds.). (2001). Transdisciplinarity: Joint problem solving among science, technology, and society. Berlin, Germany: Birkhäuser.

[29] Nicolescu, B. (2014). From modernity to cosmodernity. Albany, NY: SUNY Press.

[30] McGregor, S. L. T. (2018b). Philosophical underpinnings of the transdisciplinary research methodology. Transdisciplinary Journal of Engineering \& Science, 9, 182-198.

[31] Nicolescu, B. (2006). Transdisciplinarity: Past, present and future. In B. Haverkort \& C. Reijntjes (Eds.), Moving Worldviews - Reshaping sciences, policies and practices for endogenous sustainable development (pp. 142-166). Leusden, Netherlands: COMPAS Editions.

[32] Klein, J. T. (2014). Discourses of transdisciplinarity: Looking back to the future. Futures, 63, 68-74. 
[33] Rohmann, C. (1999). A world of ideas: A dictionary of important theories, concepts, beliefs, and thinkers. New York, NY: Ballantine Books.

[34] Cicovacki, P. (2004). Transdisciplinarity as an interactive method: A critical reflection on the three pillars of transdisciplinarity. TRANS: Internet Journal for Cultural Sciences, 15(1), http://www.inst.at/trans/15Nr/01_6/cicovacki15.htm

[35] McGregor, S. L. T. (2011). Transdisciplinary axiology: To be or not to be. Integral Leadership Review, 11(3), http://integralleadershipreview.com/3388-transdisciplinary-axiology-to-be-or-not-tobe/c_human_needs_in_home_economics.pdf

[36] Nicolescu, B. (2016). The hidden third (trans. William Garvin). New York, NY: Quantum Prose.

[37] McGregor, S. L. T. (2015b). Transdisciplinary knowledge creation. In P. T. Gibbs (Ed.), Transdisciplinary professional learning and practice (pp. 9-24). New York, NY: Springer.

[38] van Breda, J. (2007, June 2-6). Towards a transdisciplinary hermeneutics: A new way of going about the science/religion debate. Paper presented at the Eighth Annual Metanexus Conference. Philadelphia, PA. Retrieved from https://www.metanexus.net/towardstransdisciplinary-hermeneutics/

[39] Alvira, R. (2014). A unified complexity theory. Scotts Valley, CA: CreateSpace.

[40] Nicolescu, B. (2010a, June 16-19). Disciplinary boundaries - What are they and how they can be transgressed? Paper prepared for the International Symposium on Research Across Boundaries. Luxembourg: University of Luxembourg. Retrieved from http://basarab-nicolescu.fr/Docs_articles/Disciplinary_Boundaries. htm

[41] McGregor, S. L. T. (2009). Integral leadership's potential to position poverty within transdisciplinarity. Integral Leadership Review, 9(2), http://integralleadershipreview.com/4758-feature-article-integralleadership $\% \mathrm{E} 2 \% 80 \% 99$ s-potential-to-position-poverty-within-transdisciplinarity1

[42] McGregor, S. L. T. (2018a, April 27-28). Leading together for tomorrow. Keynote presented at the Alberta Human Ecology and Home Economics Association annual conference, Red Deer, Alberta.

[43] Gough, I., \& McGregor, J. A. (Eds.). (2007). Wellbeing in developing countries: From theory to research. Cambridge, England: Cambridge University Press.

[44] Millennium Ecosystem Assessment. (2005). Ecosystems and human well-being: Current state and trends. Washington, DC: Island Press.

[45] Armitage, D., Bn, C., Charles, A. T., Johnson, D., \& Allison, E. H. (2012). The interplay of well-being and resilience in applying a social-ecological perspective. Ecology and Society, 17(4), 1-15. http://dx.doi.org/10.5751/ES-04940-170415

[46] White, S. C. (2017). Relational wellbeing: Re-centring the politics of happiness, policy and the self. Policy \& Politics, 45(2), 121-136.

[47] Reed, P. G. (2003). The theory of self-transcendence. In M. J. Smith \& P. Liehr (Eds.), Middle range theories in nursing (pp. 145165). New York, NY: Springer.

[48] De Fruyt, F., Van De Wiele, L., \& Van Heeringen, C. (2000). Cloninger's psychobiological model of temperament and character and the five-factor model of personality. Personality and Individual Differences, 29(3), 441-452.

[49] Maslow, A. H. (1993). The farther reaches of human nature. New York, NY: Penguin.

[50] Kelly, S. M. (2005). Transpersonal psychology and the paradigm of complexity. Journal of Conscious Evolution, 1(1), Article 8, https://digitalcommons.ciis.edu/cejournal/vol1/iss1/8

[51] Huta, V., \& Ryan, R. M. (2010). Pursuing pleasure or virtue: The differential and overlapping well-being benefits of hedonic and eudaimonic motives. Journal of Happiness Studies, 11, 735762.

[52] Barad, K. (2003). Posthumanist performativity: Toward an understanding of how matter comes to matter. Signs: Journal of Women in Culture and Society, 28(3), 801831.

[53] Barad, K. (2007). Meeting the universe halfway: Quantum physics and the entanglement of matter and meaning. Durham, England: Duke University Press.

[54] Smith, M. J. (2003). Producing and consuming knowledge [Working paper, Open University]. Milton Keynes, England. Retrieved June 4, 2010 from the Society for Social and Political Philosophy website: http://www.sspp.us/Protected-Essays/2003-SPEP-Smith.doc 
Sue L. T. McGregor

Conceptualizing Trans Well-being within Transdisciplinarity

[55] Rosch, E. (1975). Cognitive representations of semantic categories. Journal of Experimental Psychology: General, 104(3), 192-233.

[56] McGregor, S. L. T., \& Goldsmith, E. B. (1998). Expanding our understanding of quality of life, standard of living, and well-being. Journal of Family $\&$ Consumer Sciences, 90(2), 2-6, 22.

[57] Kearns, J. N., \& Fincham, F. D. (2004). A prototype analysis of forgiveness. Personality and Social Psychology Bulletin, 30(7), 838-855.

[58] Ashley, F. (2018). Don't be so hateful: The insufficiency of anti-discrimination and hate crime laws in improving trans well-being. University of Toronto Law Journal, 68(1), 1-36.

[59] Nicolescu, B. (2010b). Methodology of transdisciplinarity. Transdisciplinary Journal of Engineering 85 Science, $1(1), 19-38$

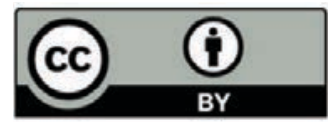

Copyright (c) 2019 by the author. This is an open access article distributed under the Creative Commons Attribution License (https://creativecommons.org/licenses/by/4.0/), which permits unrestricted use, distribution, and reproduction in any medium, provided the original work is properly cited.

\section{About the Author}

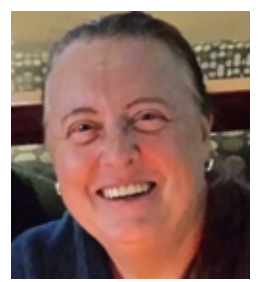

Dr. Sue L. T. McGregor (PhD, IPHE, Professor Emerita) is a Canadian home economist (nearly 50 years) retired after 30 years from Mount Saint Vincent University, Halifax NS. She has a keen interest in home economics philosophy and leadership along with transdisciplinarity, research paradigms and methodologies, and consumer studies and education. She is a ATLAS Fellow, a Rhoda H. Karpatkin International Consumer Fellow, and she received the TOPACE International Award (Berlin) for distinguished international consumer scholar, especially as consumer educator using a transdisciplinary perspective. Dr. McGregor is the recipient of Kappa Omicron Nu's (KON) Marjorie M. Brown Distinguished Professor Award (home economics leadership) and is Docent in Home Economics at the University of Helsinki (lifetime appointment in recognition of international leadership). She published Understanding and Evaluating Research (SAGE) in 2018. Her scholarship is at www.consultmcgregor.com 